\title{
Adaptation of Fetal Pulmonary Blood Flow to Local Infusion of Tolazoline
}

\author{
STEVEN H. ABMAN, RANDALL B. WILKENING, ROBERT M. WARD, AND \\ FRANK J. ACCURSO \\ Department of Pediatrics and the Webb-Waring Lung Institute, University of Colorado School of Medicine, \\ Denver, Colorado and the University of Utah School of Medicine, Salt Lake City, Utah
}

\begin{abstract}
Although tolazoline is the most commonly used drug in the treatment of neonatal pulmonary hypertension, its mode of action and efficacy remain incompletely understood. In order to study the effects of tolazoline on a high resistance pulmonary circulation and to better understand mechanisms that control pulmonary vascular tone and reactivity in the fetus, we infused tolazoline either continuously or as bolus into the left pulmonary artery of 15 chronically instrumented, normoxic fetal lambs during late gestation. The vasodilatory effects of bolus injections of tolazoline $(2.5 \mathrm{mg})$ were inhibited by the prior administration of the histaminergic receptor blockers, cimetidine $(56 \%)$, diphenhydramine $(56 \%)$, or both $(100 \%)$. During the continuous infusion of tolazoline $(4.5 \mathrm{mg} / \mathrm{h}$ for $9 \mathrm{~min})$, pulmonary blood flow to the left lung increased from $61 \pm$ $6 \mathrm{ml} / \mathrm{min}$ (mean $\pm \mathrm{SE}$; control) to $100 \pm 10$ (peak) at 30 $\min (p<0.001)$. However, following this initial vasodilatation, pulmonary blood flow steadily decreased toward control values by $90 \mathrm{~min}$, despite the continued infusion of tolazoline $(p<0.001)$. Although the calcium channel blocker, verapamil, and the $\alpha$-adrenergic blocker, phentolamine, had little effect on fetal pulmonary blood flow when infused alone, both drugs increased the vasodilatory response to tolazoline $(p<0.001)$. We conclude that tolazoline effects pulmonary vasodilatation by a histaminergic mechanism and that subsequent refractoriness to the drug is a calcium-dependent process which may be partially mediated by an $\alpha$-adrenergic mechanism. (Pediatr Res 20: 1131-1135, 1986)
\end{abstract}

\section{Abbreviations}

PPHN, persistent pulmonary hypertension of the newborn LPA, left pulmonary artery

PPHN accompanies a variety of cardiopulmonary disorders, including asphyxia, meconium aspiration, sepsis, hyaline membrane disease, and congenital diaphragmatic hernia, or occurs as an idiopathic disorder ("persistent fetal circulation") (1-6). Morbidity and mortality of PPHN remains high despite aggressive therapeutic interventions, including hyperventilation, inotropic support of the systemic circulation, and pharmacologic manipulation of the pulmonary vascular bed $(7,8)$. Attempts to find a

Received January 31, 1986; accepted June 9, 1986

Correspondence Steven H. Abman, M.D., Pediatric Pulmonary Medicine, Box C-220, University of Colorado Health Sciences Center, 4200 East Ninth Avenue, Denver, CO 80262.

Supported by grants from the American Lung Association, American Thoracic Society, the Colorado Lung Association, and National Institutes of Health Grants HD-01860 and HD-00781. vasodilator which selectively and consistently lowers pulmonary vascular resistance without causing systemic hypotension or other side effects have been unsuccessful. Despite its complex pharmacology, and although its current use is largely based on case reports or uncontrolled clinical studies, tolazoline has evolved as the primary vasoactive drug used in the treatment of PPHN (4, 5, 7, 9-12). Although many newborns with PPHN treated with tolazoline appear to initially improve oxygenation, this response is often transient $(5,11,12)$. Despite the lack of a clear etiology or pathogenetic mechanism, PPHN has been characterized by excessive muscularization of the pulmonary vasculature at autopsy and abnormal vasoreactivity (13-15). Because PPHN appears to represent failure to sustain pulmonary vasodilatation during the transition from the fetal to the neonatal circulation at birth, understanding the mechanisms which maintain high pulmonary vascular resistance in the normal fetus may provide insight regarding the pathophysiology of PPHN.

In order to study the direct effect of tolazoline on vascular tone and reactivity of the normally oxygenated fetal pulmonary circulation, we infused tolazoline into the left pulmonary artery of chronically instrumented fetal sheep, thereby achieving high drug concentrations locally while decreasing systemic drug effects. The effects of histamine, as well as calcium channel and $\alpha$ adrenergic receptor blockade on the hemodynamic effects of tolazoline were studied in order to examine the mechanisms by which tolazoline affects vascular tone.

\section{METHODS}

Surgical preparation. Fifteen mixed-breed pregnant ewes between 115-124 days gestation (term $=147$ days) were fasted for 2 days prior to surgery. Ewes were sedated with intravenous pentobarbital and anesthetized by lumbar intrathecal injection of $1 \%$ tetracaine $\mathrm{HCl}(3 \mathrm{mg})$. The uterus was delivered under sterile conditions, and the fetal left forelimb was delivered through a uterine incision. A left thoracotomy was then performed. A cuff-type electromagnetic flow transducer (Micron Instruments, Los Angeles, CA) was placed around the LPA to measure blood flow to the left lung. Polyvinyl catheters were inserted into the left pulmonary artery $(0.043$ inch OD), main pulmonary artery (0.054 inch OD), and left atrium $(0.054$ inch $\mathrm{OD}$ ) by direct puncture following the placement of purse string sutures. These catheters were guided into position through a no. 16 gauge Angiocath intravenous catheter modified to minimize blood loss. The catheters were secured by tightening the purse string. The LPA catheter was inserted at the bifurcation of the main pulmonary artery and ductus arteriosus. The main pulmonary artery catheter was inserted between the ductus arteriosus and pulmonic valve. The left atrial catheter was placed in the medial portion of the left atrial appendage. A second small hysterotomy was performed in order to place catheters $(0.054$ inch $O D)$ in the abdominal aorta and inferior vena cava via the 
pedal artery and vein. Catheter position was confirmed at autopsy. A catheter ( 0.054 inch OD) was also placed in the amniotic cavity to measure pressure. The catheters and flow transducer cables were exteriorized via subcutaneous tunnels to an external flank pouch. Ampicillin $(500 \mathrm{mg})$ and Streptomycin $(1 \mathrm{~g})$ were given intramuscularly immediately following surgery. Animals were standing and feeding in their individual pens by $6 \mathrm{~h}$ postoperatively. Ewes were fed ad libitum. Catheters were maintained by flushing 1-3 $\mathrm{ml}$ heparinized saline $(35 \mathrm{U} / \mathrm{ml})$ daily.

Experimental design. Studies were performed after a postoperative recovery period of at least $72 \mathrm{~h}$. Flow transducer cables were attached to an internally calibrated flowmeter (Micron Instruments) providing a continuous measurement of left pulmonary artery blood flow. Absolute values of flow were calculated on the observation that flow was zero at end-diastole (1618). However, although relative changes in flow from baseline can be accurately measured by this technique, absolute values of flow at baseline can have a wide range of error (16). Correlation between end-diastolic flow and zero flow was obtained by measuring pulmonary blood flow while six animals were sacrificed. The signal measured at the time of fetal death was in good agreement with the measured flow at end-diastole (mean difference $=13.3 \mathrm{ml} / \mathrm{min}$ ).

Amniotic, aortic, main pulmonary artery and left atrial catheters were connected to Gould-Statham P231D pressure transducers, and calibrated immediately prior to each study using a mercury column manometer. Pressures were referenced to the amniotic cavity pressure. Heart rate was determined continuously by cardiotachometer or determined from phasic pulmonary blood flow tracings. Signals were continuously recorded on a Gould chart recorder. All drugs were infused through the left pulmonary artery catheter. Each experimental protocol was performed only once in each animal.

Response to the continuous infusion of tolazoline. Tolazoline $\mathrm{HCl}$ (CIBA-Geigy, Summit, $\mathrm{NJ}$ ) was diluted in normal saline from a stock solution prior to each infusion. Continuous infusion was regulated by gravimetrically calibrated infusion pumps (Sage Instruments). Tolazoline was administered at $4.5 \mathrm{mg} / \mathrm{h}$ at flows of $6 \mathrm{ml} / \mathrm{h}$. This dose was selected empirically because it provided an adequate rise in pulmonary blood flow during prolonged local infusion without causing systemic hypotension or bradycardia. Serial blood samples were obtained for serum tolazoline levels in three animals. Arterial blood gases were determined from samples drawn through the main pulmonary artery catheter obtained before, during, and after the tolazoline infusions (four animals). To evaluate the length of the refractory period, a second infusion of a fresh solution of tolazoline $(4.5 \mathrm{mg} / \mathrm{h})$ was performed following a 30 -min recovery period ( $n=$ four animals). Blood flow during the first and second infusion periods were compared at 20 min because that was the time of peak flow during the second infusion.

Pharmacokinetics of tolazoline. The pharmacokinetics of tolazoline in three fetal sheep were determined by serial measurements of left atrial samples by a gas chromatography-mass spectrometry technique (19). Samples were drawn into EDTA-containing syringes, placed on ice, and then centrifuged within 30 min of the draw. Plasma was removed, stored at $-70^{\circ}$, and shipped on dry ice for assay (RMW).

Effects of histaminergic receptor blockade on the response to the bolus administration of tolazoline. The responses of left pulmonary artery blood flow to injections of tolazoline $(2.5 \mathrm{mg}$ into the left pulmonary artery catheter) were measured before and after infusions of the H1-blocker, diphenhydramine $(10 \mathrm{mg}$ over $10 \mathrm{~min}$; Bristol, Syracuse, NY), and the H2-blocker, cimetidine $(40 \mathrm{mg}$ over $10 \mathrm{~min}$; Smith Kline and French, Philadelphia, PA). Dose selection was based on previous studies from our laboratory demonstrating effective blockade to rapid bolus injections of histamine (20), as well as published studies on newborn lambs (21). For each study, the values of peak flow from three injections of tolazoline at 10 -min intervals were averaged prior to the infusion of the histamine receptor antagonist. Each animal received either diphenhydramine (four animals) or cimetidine (five animals) as the first blocker. Two boluses of tolazoline were injected following blockade at intervals determined by the time required for flow to return to baseline levels. To achieve complete histaminergic blockade, the other antagonist was then given, followed by tolazoline boluses. No other drugs were given on the day that these studies were performed.

Effect of calcium channel blockade. In five animals, the hemodynamic response to tolazoline $(4.5 \mathrm{mg} / \mathrm{h})$ was compared with the response to a combined infusion of verapamil $(240-300 \mu \mathrm{g} /$ h) (Searle, Chicago, IL) with tolazoline $(4.5 \mathrm{mg} / \mathrm{h})$ over $90 \mathrm{~min}$. The dose of verapamil was established empirically; prolonged infusion of higher doses frequently led to bradycardia and systemic hypotension, especially in less mature animals. In each animal, studies were performed on separate days, at intervals of 1 (three animals), 2 (one animal), or 4 days (one animal). At the time of study, the mean gestational age was 132 days for the tolazoline infusion (range 125-139 days) and 133 days for the combined infusion (range 126-140 days).

Effect of $\alpha$-adrenergic blockade. In six animals, phentolamine (CIBA-Geigy) was infused at $0.1 \mathrm{mg} / \mathrm{min}$ for $90 \mathrm{~min}$ prior to and during tolazoline infusion $(4.5 \mathrm{mg} / \mathrm{h})$. This dose was selected because it consistently blocks the pulmonary vasoconstrictor response to methoxamine $(500 \mu \mathrm{g})$. Each animal received tolazoline or tolazoline with phentolamine on separate days. Studies were performed within 1 day of each other. Three animals received tolazoline on the first study day (mean gestational age 131 days; range 125-139 days), while three were studied with tolazoline plus phentolamine first (mean age 131 days; range 125-138 days).

Statistical analysis. Statistical analysis of the data was performed by two-way analysis of variance for repeated measures. This method allows for multiple comparisons by the use of appropriate contrasts $(22,23)$. Different periods of the study were compared by partition of the between times sum of squares for comparison of changes in each variable at different times during the study (22). Means for baseline, infusion, and recovery periods were compared for each variable (including flow, pulmonary artery and aorta pressures, heart rate, and arterial blood gases). Furthermore, means at individual time points were compared with means for periods during the study; the blood flow at 30 min into the tolazoline infusion was compared with the entire baseline period, as was flow at the end of the tolazoline infusion. The method was also used to test whether variables remained constant during a given time period or changed in linear or quadratic fashion. As each animal served as its own control for studies involving verapamil and phentolamine, the method was also applied to compare time periods of tolazoline infusions alone versus tolazoline infusion with verapamil or phentolamine. The analysis takes into account several time points during each period for each variable, and therefore can detect small differences between periods. All statistical comparisons were performed using the SAS statistical computing package on a VAX 11 minicomputer (23). A significant difference was judged as $p$ value less than 0.05 .

\section{RESULTS}

Continuous tolazoline infusion. The hemodynamic response to the continuous infusion of tolazoline into the left pulmonary artery is illustrated in Figure 1. Values are expressed as mean \pm $\mathrm{SE}$. Following baseline measurements for $30 \mathrm{~min}$, the infusion of tolazoline rapidly increased flow from $61 \pm 6 \mathrm{ml} / \mathrm{min}$ (mean $\pm \mathrm{SE})$ to a peak flow at $30 \mathrm{~min}$ of $100 \pm 10 \mathrm{ml} / \mathrm{min}(p<0.001)$. However, despite the continued infusion of tolazoline, flow steadily decreased linearly toward baseline values $(p<0.001)$. After $90 \mathrm{~min}$, flow was not significantly different from the preinfusion flow $(62 \pm 4 \mathrm{ml} / \mathrm{min} ; p>0.05)$. Heart rate linearly 

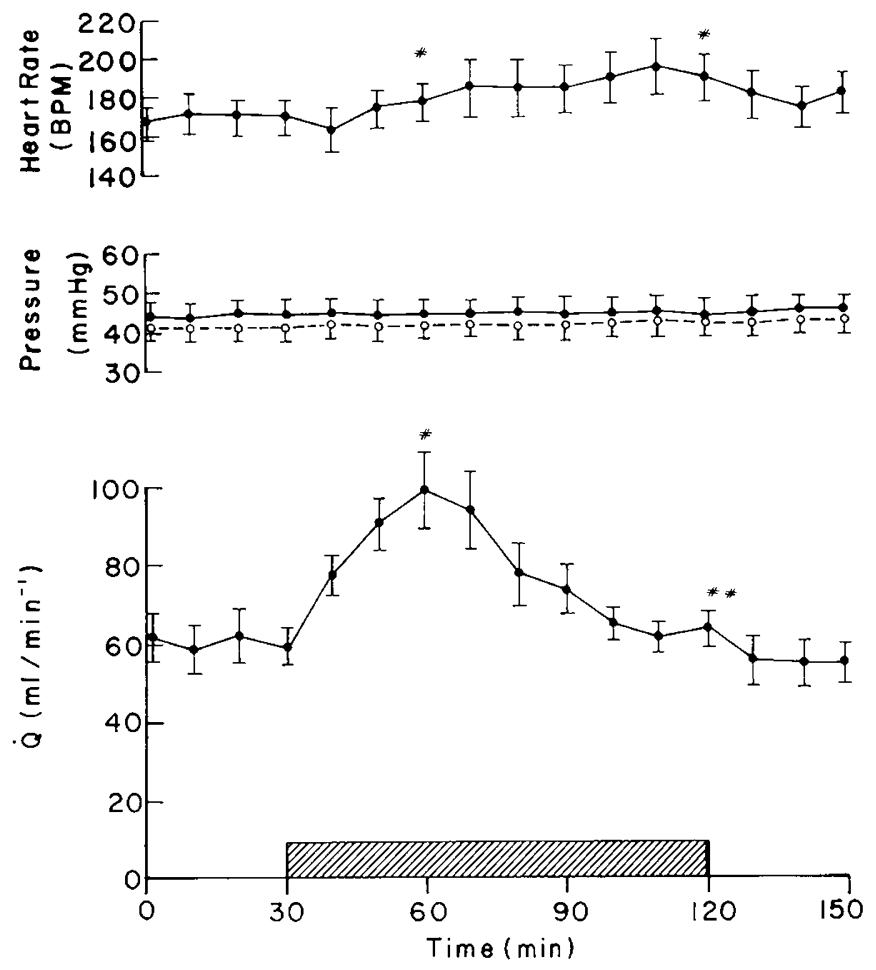

Fig. 1. The hemodynamic response to the continuous infusion of tolazoline into the LPA of fetal lambs ( $n=9$ animals). Left pulmonary artery blood flow (mean \pm SEM) during the 90 -min infusion period are plotted versus time in the lower panel. Mean pulmonary artery

-) and aortic pressures $\left(\mathrm{O}_{-}-\mathrm{O}\right)$ and heart rate are depicted in the middle and upper panels, respectively. The hatched area represents the infusion period. Comparisons shown are made between baseline and study values at 60 and $120 \mathrm{~min}(\#=\mathrm{p}<0.001$; \#\# $=p>0.05$; analysis of variance.

increased during the infusion, from $171 \pm 9 \mathrm{bpm}$ (baseline) to $187 \pm 21$ at $40 \mathrm{~min}(p<0.05)$, and remained elevated until the tolazoline infusion was discontinued. Mean main pulmonary artery and aortic pressures did not change during the infusion (Fig. 1). Furthermore, the difference between main pulmonary artery and aortic pressures did not change, suggesting no apparent ductal closure. Left atrial pressure was measured in five animals and remained constant throughout the study $(2-4 \mathrm{~mm} \mathrm{Hg})$. Serial arterial blood gases from the main pulmonary artery were obtained before, during, and after the tolazoline infusion in four animals. Initial $\mathrm{pH}$ was $7.42 \pm 0.01, \mathrm{pO}_{2}$ was $19.5 \pm 0.6$ torr, and $\mathrm{pCO}_{2}$ was $46.8 \pm 1.5$ torr. No significant changes were found during and after the tolazoline infusion. The same pattern of increased flow followed by rapid adaptation was seen in each individual animal studied and at all gestational ages (from 120 to 140 days). The four animals that received a second infusion of tolazoline following a $30-\mathrm{min}$ recovery period demonstrated a diminished vasodilatory response in comparison with the initial infusion. Flow increased slightly from a mean baseline of $70.2 \pm$ $9.8 \mathrm{ml} / \mathrm{min}$ to a peak flow of $82.5 \pm 10.2 \mathrm{ml} / \mathrm{min}$ at $20 \mathrm{~min}(p$ $<0.05$ ). Flow at $20 \mathrm{~min}$, however, was significantly less in comparison with the first infusion $(116.8 \pm 10.1 \mathrm{ml} / \mathrm{min} ; p<$ $0.01)$.

Pharmacokinetics of tolazoline during continuous infusion. In three animals, measurements of tolazoline from left artery samples were made before, during, and after tolazoline infusion at 15-min intervals (gestational ages $=124,126$, and 134 days). During the infusion, concentrations steadily increased, peaking at $0.54 \pm 0.01 \mathrm{mg} /$ liter (mean $\pm \mathrm{SE}$ ) (range 0.53 to 0.56 ). Mean half-life was $50.3 \mathrm{~min}$.
Effects of histaminergic blockade on response to bolus injections of tolazoline. Figure 2 illustrates the effects of $\mathrm{H} 1, \mathrm{H} 2$, and combined $\mathrm{H} 1$ and $\mathrm{H} 2$ blockade on the vasodilatory response to the bolus injection of tolazoline. Tolazoline-induced increase in flow was reduced $56 \%$ by diphenhydramine and $56 \%$ by cimetidine $(p<0.001)$. The administration of both agents completely inhibited the tolazoline-induced vasodilatation $(p<0.001)$. Infusion of the blockers alone did not alter baseline flow. Small boluses of tolazoline $(2.5 \mathrm{mg})$ injected at 10 -min intervals do not lead to apparent tachyphylaxis.

Effects of verapamil infusion. The continuous infusion of verapamil into the left pulmonary artery did not alter flow, heart rate, and main pulmonary artery and aortic pressures at the doses used in this study $(40-80 \mu \mathrm{g} / \mathrm{min})$. Infusion of verapamil with tolazoline, however, sustained the rise in flow throughout the 90 min infusion when compared with the response to tolazoline alone $(p<0.001$; Fig. 3). Baseline flows were similar in both groups. However, unlike the response to tolazoline alone, flow at $90 \mathrm{~min}$ was significantly different from baseline flow (107 \pm 11 versus $61 \pm 11 \mathrm{ml} / \mathrm{min} ; p<0.01$ ).

Increased heart rate during infusions of tolazoline and tolazo-

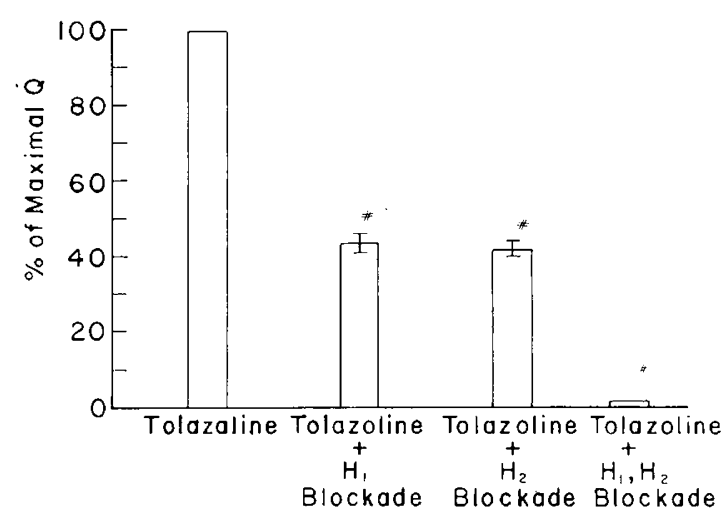

Fig. 2. Effect of $\mathrm{H} 1, \mathrm{H} 2$, or combined receptor blockade on the response of pulmonary blood flow to bolus injections of tolazoline $(2.5$ $\mathrm{mg}$ ) into the LPA. Data are expressed as percent of maximal flow $(Q)$, with the increase in $Q$ following tolazoline without blockade representing $100 \%$. Comparisons are made between tolazoline alone versus tolazoline plus $\mathrm{H} 1$ blockade (diphenhydramine, $10 \mathrm{mg}$ ), tolazoline plus $\mathrm{H} 2$ blockade (cimetidine, $30 \mathrm{mg}$ ), and tolazoline plus combined blockade (diphenhydramine plus cimetidine) (\# $=p<0.001$; analysis of variance).

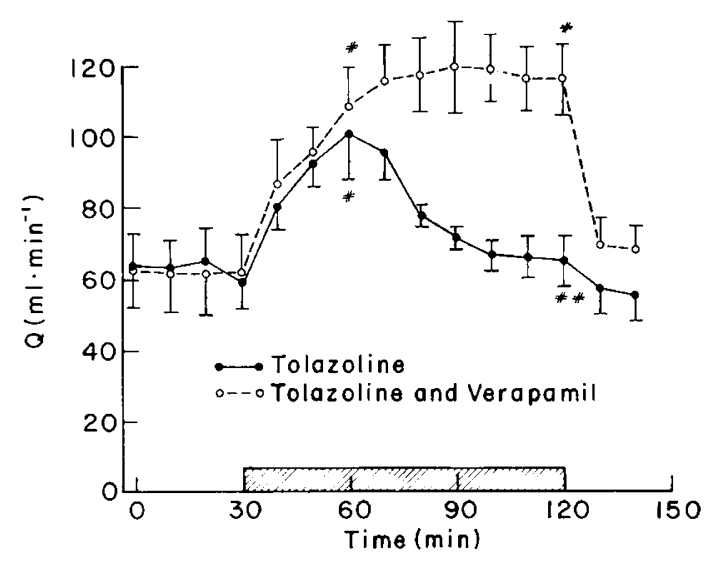

Fig. 3. Hemodynamic response to the combined infusion of tolazoline with verapamil into the LPA of fetal lambs ( $n=$ five animals). The hatched area represents the treatment period. The response to tolazoline plus verapamil was significantly greater than tolazoline alone $(p<0.001$; repeated measures by analysis of variance) $(\#=p<0.001$; \#\# $=p>$ 0.05 in comparison to baseline values). 
line plus verapamil were similar. Although pulmonary artery and aortic pressures did not change from control values with tolazoline alone, there was a small but statistically significant fall in mean pulmonary artery pressure $(53.3 \pm 1.8$ to $51.2 \pm 3.2$ $\mathrm{mm} \mathrm{Hg} ; p<0.05)$ and aortic pressures $(50.6 \pm 1.8$ to $48.6 \pm 3.1$ $\mathrm{mm} \mathrm{Hg} ; p<0.05$ ) during the combined infusion.

Effects of phentolamine infusion. In six animals, the responses to tolazoline infusions over $90 \mathrm{~min}$ were compared to the responses of tolazoline infusion with $\alpha$-adrenergic blockade from phentolamine (Fig. 4). Although heart rate increased, phentolamine infusion $(0.1 \mathrm{mg} / \mathrm{min}$ for $90 \mathrm{~min})$ into the LPA did not significantly alter flow or main pulmonary artery or aortic pressures. When tolazoline $(4.5 \mathrm{mg} / \mathrm{h})$ was infused with phentolamine (after a $90-\mathrm{min}$ pretreatment period of phentolamine alone), flow was more sustained in comparison to infusions of tolazoline alone $(p<0.01)$. However, a steady decline in flow still occurred.

\section{DISCUSSION}

Our results show that tolazoline is a pulmonary vasodilator in the chronically instrumented, normally oxygenated fetal sheep, and, as observed in the hypoxic newborn lamb (21), this vasodilatation is mediated by histamine receptors. With the prolonged infusion of tolazoline, an adaptation occurs, such that pulmonary blood flow returns to preinfusion values despite continued exposure to increasing concentrations of the drug. The pulmonary circulation remains relatively refractory to a second infusion of tolazoline for at least $30 \mathrm{~min}$ after the first infusion is completed. When administered with tolazoline, verapamil prolongs the vasodilatory effect, with pulmonary blood flow being sustained throughout the 90 -min infusion period of these experimental conditions. Phentolamine also augments tolazoline's vasodilatory effect, but pulmonary blood flow is not sustained throughout the infusion period. Neither verapamil nor phentolamine affected pulmonary blood flow when infused without tolazoline.

Despite the widespread use of tolazoline over the past $21 \mathrm{yr}$ (9), its mechanism of action and efficacy in treating neonatal pulmonary hypertension remains unclear (24). "Tachyphylaxis" to tolazoline, described as the failure to sustain improvement in oxygenation and other parameters following an initial positive response to therapy, is a common clinical problem. The clinical significance of this problem may be related to the poor correlation between the initial response to tolazoline and subsequent outcomes reported in many studies $(5,11,12)$.

The failure to sustain vasodilatation despite the continuous infusion of tolazoline may reflect its diverse pharmacologic prop-

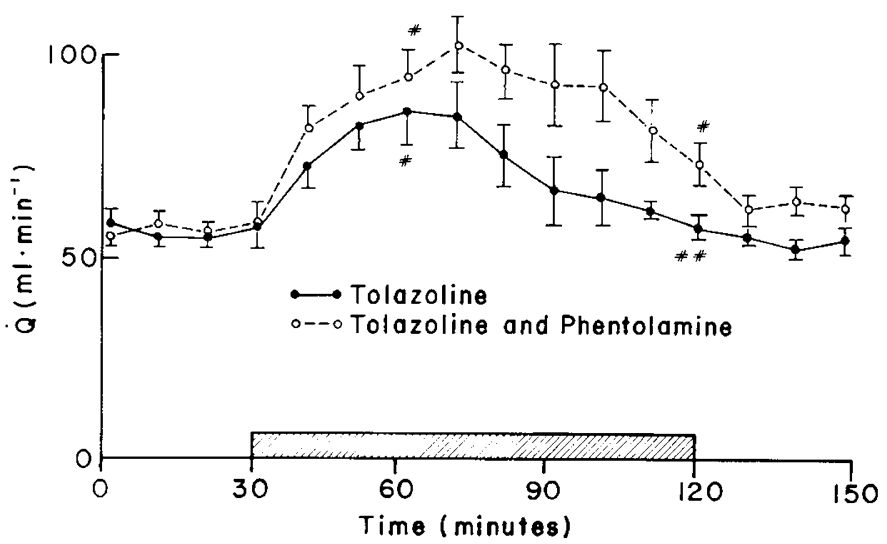

Fig. 4. Effect of phentolamine infusion on the vasodilatory response to tolazoline $(n=6)$. Hatched area represents treatment period. Statistical comparisons are made with the response of $\mathrm{Q}$ to tolazoline infusions without phentolamine in the same animals $(p<0.01$; analysis of variance). (\# = $p<0.01$; \#\#=p>0.05; in comparison to baseline values). erties or reflect traits intrinsic to the fetal pulmonary circulation. Tolazoline is a complex pharmacologic agent, possessing a variety of adrenergic and histaminergic actions, whose overall effect is dependent on such variables as anesthetic agent (25), age (25), dose, baseline pulmonary vascular tone (26), and route of administration. Further difficulty in understanding tolazoline's properties may result from the release of endogenous histamine or catecholamines which may modulate its effects (27). Tachyphylaxis due to the down-regulation of histamine receptors is one possible explanation of the adaptation to the continuous infusion of tolazoline. However, failure to sustain vasodilatation is not unique to tolazoline and has been observed with such diverse agents as small increases in arterial oxygen tension (28), acetylcholine $(29,30)$, bradykinin (29), histamine (29), and prostaglandins 12, D2, and E1 (31). Although the exact mechanism of this adaptation is not clear, the augmented response to tolazoline with $\alpha$-adrenergic blockade suggests that vasoconstriction may result from $\alpha$-adrenergic stimulation from circulating catecholamines or increased neural tone. A similar mechanism may cause the reflex pulmonary vasoconstriction which follows mechanical distension of the main pulmonary artery in newborn lambs (32). It is also possible that tolazoline's $\alpha$-adrenergic agonist effects become more pronounced during prolonged infusion or with reduced pulmonary vascular resistance (26). Whether $\alpha$ adrenergic blockade augments the vasodilatory response to other agents, such as small increases in oxygen, is not known.

An alternate explanation to the steady decrease in pulmonary blood flow despite tolazoline's continuous infusion is that cardiac output is steadily decreasing at higher drug concentrations. Cardiac output was not measured in these studies; however, it seems unlikely that this would explain these findings. Pulmonary vascular resistance is calculated by the difference between pulmonary artery and left atrial pressures divided by flow. In the absence of significant changes in pulmonary artery and left atrial pressures, altered pulmonary blood flow directly reflects changes in pulmonary vascular resistance.

Although tachyphylaxis to the continuous infusions of tolazoline in fetal lambs has been noted (30), this process had not been studied systematically. Previous studies have examined the effect of tolazoline in hypoxic newborn animals $(16,21,33)$. Goetzman and Milstein (21) demonstrated its vasodilating properties in newborn lambs with hypoxic pulmonary vasoconstriction, noting that although tolazoline was generally regarded as an $\alpha$-adrenergic blocker, its effects involved histamine receptors. Lock et al. (16) demonstrated that tolazoline directly dilates pulmonary vasculature constricted by hypoxia, but that some of the response was indirect, secondary to an improved cardiac output and related changes, such as recruitment or improved mixed venous $\mathrm{pO}_{2}$. Interestingly, both studies administered tolazoline as bolus infusions and found short durations of action, leading to the speculation that "a reflex mechanism" (21) or "multiple vascular control mechanisms" (16) exist in the hypoxic newborn lamb that keep the vascular bed in a constricted state. In the only reported study of prolonged infusion in the hypoxic newborn lamb, however, tolazoline's vasodilating effect was sustained throughout a 2-h infusion period (33). In comparison with other known fetal pulmonary vasodilators, and as seen with hypoxic newborn lambs (34), tolazoline's potency is poor, even with the infusion directly into the LPA. Furthermore, the magnitude of the response remained small, even when augmented with calcium-channel or $\alpha$-adrenergic blockade.

Since the early reports demonstrating inhibition of hypoxic pulmonary vasoconstriction in animal models (35) and efficacy in treating some adults with primary pulmonary hypertension, calcium channel blockers have been considered as potential therapeutic agents in treating PPHN. Recent studies in newborn animals, however, have demonstrated that although calciumchannel blockers appear to have some pulmonary vasodilating properties, the effect on vascular tone is not selective, and systemic hypotension is a common problem (36-39). We initially 
studied verapamil in order to examine the response of the fetal pulmonary vascular bed to its local infusion. Finding no significant change in pulmonary vascular resistance, we then infused it with tolazoline in order to study the role of calcium in the adaptation mechanism. Although the vasodilatory effect of tolazoline was augmented by verapamil infusion, the specific site of action is not known, and further studies will be necessary to delineate the mechanism of adaptation and the role of calcium. Although the possible therapeutic role of calcium channel blockade has been suggested (35), several animals not included in our analysis demonstrated marked bradycardia and hypotension during prolonged infusions of tolazoline and verapamil, suggesting that this combination may be poorly tolerated, especially in the asphyxiated newborn. Furthermore, bradycardia and hypotension have been reported in infants treated with verapamil for supraventricular tachycardia (40). Similarly, although the combined infusion of tolazoline and phentolamine augmented pulmonary blood flow in the fetal lamb, its potential therapeutic role remains unknown.

The ability of the fetal pulmonary circulation to restore its vascular tone to its initial constricted state in the face of increasing concentrations of tolazoline illustrates the complexity of factors regulating vascular tone. Lock et al. (16), for example, demonstrated that alterations in the resting tone of the newborn lamb's pulmonary circulation altered its response to catecholamine infusion (41). Teleologically, it is not surprising that mechanisms maintaining high pulmonary vascular resistance exist in the fetus, since the lung does not perform gas exchange functions, and high flow in gestation may adversely affect lung development. We speculate that the persistence of such a mechanism may be pathogenic in PPHN, suggesting the importance of studies examining pulmonary vasoreactivity in utero as well as in the newborn animal.

Acknowledgment. The authors are grateful to the statistical support provided by Gary Zerbe, Ph.D., Department of Biometrics, UCHSC.

\section{REFERENCES}

1. Brown R, Pickering D 1974 Persistent transitional circulation. Arch Dis Child 49:883-887

2. Chu J, Clements JA, Cotton EK, Klaus M, Sweet A, Thomas M, Wooley W, Wright K 1965 Pulmonary hypoperfusion syndrome. Pediatrics 35:733-742

3. Fox WW Gewitz MH, Dinwiddie R, Drummond WH, Peckham GJ 1977 Pulmonary hypertension in the perinatal aspiration syndromes. Pediatrics 59:205-211

4. Gersony WM, Duc CV. Sinclair JD 1969 PFC syndrome. Circulation 40(suppl 3):87

5. Goetzman BW, Sunshine P, Johnson JD, Wennberg RP, Hackel A, Merten DF, Bartoletti A, Silverman NH 1976 Neonatal hypoxia and pulmonary vasospasm: Response to tolazoline. J Pediatr 89:617-621

6. Riemenschneider TA, Nielsen HC. Ruttenberg HD. Jaffe RB 1976 Disturbances of the transitional circulation: spectrum of pulmonary hypertension and myocardial dysfunction. J Pediatr 89:622-625

7. Drummond WH, Gregory GA, Heymann MA, Phibbs RA 1981 Independent effects of hyperventilation, tolazoline, and dopamine in infants with persistent pulmonary hypertension. J Pediatr 68:603-611

8. Peckham GJ, Fox WW 1978 Physiologic factors affecting pulmonary artery pressure in infants with persistent pulmonary hypertension. J Pediatr 93:1005-1010

9. Cotton EK 1965 Use of priscoline in the hypoperfusion syndrome. Pediatrics $36: 149$

10. Korones SB, Fabien GA 1975 Successful treatment of PFC with tolazoline. Pediatr Res 9:367

11. Stevens DC, Schreiner RL, Bull MJ, Bryson CQ, Lemons JA, Gresham EL,
Grosfeld J, Weber TR 1980 Analysis of tolazoline therapy in the criticallyill neonate. J Pediatr Surg 15:964-970

12. Stevenson DK, Kastings DS, Darnall RA, Ariagno RL, Johnson JD, Malachowski N, Beets CL, Sunshine P 1979 Refractory hypoxemia associated with neonatal pulmonary disease: The use and limitation of tolazoline. J Pediatr 95:595-599

13. Geggel RL, Reid LM 1984 Structural basis of PPHN. Clin Perinatol 11:525549

14. Levin DL, Hyman AI, Heymann MA, Rudolph AM 1978 Fetal hypertension and the development of increased pulmonary vascular smooth muscle. J Pediatr 92:265-269

15. Murphy JD, Rabinovitch M, Goldstein JD, Reid LM 1981 The structural basis of persistent pulmonary hypertension of the newborn infant. J Pediatr 98:962-968

16. Lock JE, Coceani F, Olley PM 1979 Direct and indirect pulmonary vascular effects of tolazoline in the newborn lamb. $J$ Pediatr 95:600-605

17. Lewis AB, Heymann MA, Rudolph AM 1976 Gestational changes in pulmonary vascular responses in fetal lambs in utero. Circ Res 39:536-541

18. Anderson DF, Bissonnette JM, Farber JJ, Thornberg KL 1981 Central shunt flows and pressures in the mature fetal lamb. Am J Physiol 14:60-66

19. Ward RM, Cooper MJ, Mirkin BL 1982 Determination of tolazoline in plasma by gas chromatography-mass spectrometry. J Chromatogr 231:445-450

20. Truog R, Accurso FJ, Wilkening RB, Meschia G 1984 Fetal pulmonary vasodilation with histamine: mediation by $\mathrm{H} 1$ and $\mathrm{H} 2$ receptors. Pediatr Res 18:161A

21. Goetzman BW, Milstein JM 1979 Pulmonary vasodilator action of tolazoline. Pediatr Res 13:942-944

22. Snedecor GW, Cochran G 1967 Statistical Methods. Iowa State University Press, Ames, IA, pp 301-310

23. SAS User's Guide: Statistics-1982 edition. SAS Institute, Cary, NC

24. Ward RM 1984 Pharmacology of tolazoline. Clin Perinatol 11:703-713

25. Tucker A, Brown DT, Greenless KJ 1982 Pulmonary and systemic vascular actions of tolazoline in anesthetized dogs. Pediatr Pharmacol 2:231-243

26. Sanders J, Miller DD, Patil PN 1975 Alpha-adrenergic and histaminergic effects of tolazoline-like imidazolines. J Pharm Exp Ther 195:362-371

27. Hughes MJ, O'Brien LJ 1977 Liberation of endogenous compounds by tolazoline. Agents Actions 7:225-230

28. Accurso FJ, Alpert B, Wilkening RB, Peterson R, Meschia G 1986 Time dependent course of fetal pulmonary blood flow to an increase in fetal oxygen tension. Respir Physiol 63:43-52

29. Accurso FJ, Truog RG, Wilkening RB, Meschia J 1984 Adaptation of fetal pulmonary blood flow to pharmacologic vasodilators. Pediatr Res 18:385A

30. Rudolph AM 1977 Fetal and neonatal pulmonary circulation. Am Rev Respir Dis 115:11-18

31. Abman SH, Accurso FJ, Wilkening RB 1985 Temporal response of the fetal pulmonary circulation to local infusion of arachidonic acid and prostaglandins. Am Rev Respir Dis 131:A255

32. Baylen BG, Emmanouilides GC, Juratsch CE, Yoshida Y, French WJ, Curley JM 1980 Main pulmonary artery distension: a potential mechanisms for acute pulmonary hypertension in the human newborn infant. $J$ Pediatr 96:540-544

33. Bressack MA, Bland RD 1981 Intravenous infusion of tolazoline reduces pulmonary vascular resistance and net fluid filtration in the lungs of awake, hypoxic lambs. Am Rev Respir Dis 123:217-221

34. Tripp ME, Drummond WH, Heymann MA, Rudolph AM 1980 Hemody namic effects of pulmonary arterial infusion of vasodilators in newborn lambs. Pediatr Res 14:1311-1315

35. McMurtry IF, Davidson AB, Reeves JT, Grover RF 1976 Inhibition of hypoxic pulmonary vasoconstriction by calcium antagonists in isolated rat lungs. Circ Res 38:99-108

36. Dickstein PJ, Trindade O, Goldbert RN, Bancalari E 1984 Effect of calcium antagonists on hypoxic pulmonary hypertension in the piglet. Pediatr Res 18:1262-1265

37. Milstein JM, Goetzman BW 1984 Pulmonary vascular response to digoxin in newborn lambs. Pediatr Pharmacol 4:223-229

38. Phillips JB, Lyrene RK, Leslie GI, McDeritt M, Cassady G 1985 Hemodynamic effects of nifedipine in normoxic and hypoxic newborn lambs. Pediatr Pharmacol 5:23-30

39. Redding GJ, Tuck R, Escourrou P 1984 Nifedipine attenuates acute hypoxic pulmonary vasoconstriction in awake piglets. Am Rev Respir Dis 129:785789

40. Shahar E, Barzilan Z, Frank M 1981 Verapamil in the treatment of paroxysmal supraventricular tachycardia in infants and children. J Pediatr 98:323

41. Lock JE, Coceani F, Olley PM 1981 Enhanced beta-adrenergic receptor responsiveness in the hypoxic neonatal pulmonary circulation. Am J Physiol 240:H697-703 